DOI: $10.12737 / 19965$

УДК 621.825: 630

ОСНОВНЫЕ ПОЛОЖЕНИЯ ВЫБОРА ПРЕДОХРАНИТЕЛЬНОГО УСТРОЙСТВА ДЛЯ ЛЕСОХОЗЯЙСТВЕННЫХ МАШИН

кандидат технических наук, доцент Н. А. Бородин ${ }^{1}$

кандидат технических наук, доцент А. В. Князев ${ }^{1}$

кандидат технических наук В. В. Ткачев ${ }^{1}$

кандидат технических наук, доцент И. В. Четверикова ${ }^{1}$

1 - ФГБОУ ВО «Воронежский государственный лесотехнический университет имени Г.Ф. Морозова»,

г. Воронеж, Российская Федерация.

Указано, что лесохозяйственные машины работают в сложных условиях и испытывают частые динамические перегрузки в результате попадания в рабочие органы камней, древесных отходов, инородных тел и др., которые могут привести к поломке рабочих органов, привода и отдельных частей машины. Одним из проблемных узлов в лесохозяйственных машинах являются кулачковые предохранительные муфты, применяемые для их защиты от перегрузок, они имеют существенные недостатки, так как не обеспечивают надежную защиту последних от перегрузок, что приводит к снижению производительности и дополнительным затратам на ремонт. Указано, что применение размыкающихся предохранительных муфт предельного момента в значительной мере повысит эффективность защиты лесохозяйственных машин от перегрузок, так как динамические нагрузки при пробуксовке муфты будут равны нулю. Рассмотрены основные характеристики, по которым можно оценить работу предохранительных муфт. Предлагается технические объекты рассматривать во взаимодействии с внешней средой. Указано, что при выборе средств защиты от перегрузок необходимо использовать опыт создания предшествующих образцов. Отмечено, что вопрос выбора типа предохранительного устройства тесно связан с одним из наиболее сложных положений - с выбором уровня параметра защиты. Рассмотрено, что установка предохранительных муфт должна осуществляться в непосредственной близости к месту приложения нагрузки, так как передаточное отношение до места приложения нагрузки должно быть постоянно. Приведены рекомендации по регулированию муфты на заданный момент ограничения нагрузки, чтобы не было ложных срабатываний муфты. Рассмотрены классификации предохранительных муфт по ряду признаков.

Ключевые слова: лесохозяйственная машина, предохранительная муфта, перегрузки, рабочие органы.

\title{
THE MAIN PROVISIONS OF THE CHOICE OF SAFETY DEVICES FOR FORESTRY MACHINES
}

\author{
$\mathrm{PhD}$ in Engineering, Associate Professor N. A. Borodin ${ }^{1}$ \\ $\mathrm{PhD}$ in Engineering, Associate Professor A. V. Knyazev ${ }^{1}$ \\ $\mathrm{PhD}$ in Engineering V. V. Tkachev ${ }^{1}$ \\ $\mathrm{PhD}$ in Engineering, Associate Professor I. V. Chetverikova ${ }^{1}$ \\ 1 - Federal State Budget Education Institution of Higher Education «Voronezh State University of \\ Forestry and Technologies named after G.F. Morozov», Voronezh, Russian Federation
}

\begin{abstract}
Stated that forestry machines working in difficult conditions and experiences of maintaining frequent dynamic loads as a result of getting into the working parts of stone, wood wastes, foreign bodies, etc., which can lead to breakage of the working bodies, actuators and separate parts of the machine. One of the problem nodes in the forestry machines are jaw slip clutch used to protect them from overloading, they have significant drawbacks, as it does not provide reliable protection from overloads, resulting in decreased performance and additional repair costs. Indicated that the use of a separate torque limiting torque limit will significantly increase the efficiency of protection forest machinery from overload as dynamic loads at slippage of the coupling will be zero. The basic characteristics by which one can assess the work safety clutches. Proposed technical objects to consider in the interaction with the external environment. Stated that the choice of protection against overloads it is necessary to use the experience of building the previous samples. It is noted that the question of choosing the type of safety device is closely linked to one
\end{abstract}




\section{Технологии. Машины и оборудование}

of the most difficult provisions - the choice of the level of the parameters of protection. Considered that the installation of the safety coupling must be carried out in close proximity to the place of application of the load as a ratio to the point of application of the load should be constant. Recommendations for regulation of coupling at a given point of the load limiter to avoid false positives of the coupling. Classification of safety clutches on a number of grounds.

Keywords: Forestry machine, safety clutch, overload, working bodies

Функциональное назначение предохранительных муфт - обеспечение полной и надежной передачи рабочей нагрузки с использованием (максимальных) потенциальных возможностей лесохозяйственных машин и возможностью защитить рабочие органы и приводы от нарушения нормального режима работы [1]. Наиболее важное требование - обеспечить надежную работу при срабатывании.

Работу предохранительных муфт следует оценивать следующими основными характеристиками $[2,3]$ :

1. Коэффициентом, характеризующим воздействия предохранителя на объект защиты, представляющим отношение максимального момента Тдс, установившегося после срабатывания, к моменту Тср, при котором предохранитель срабатывает.

$$
\kappa_{\text {дс }}=\frac{\mathrm{T}_{\text {дc }}}{\mathrm{T}_{\mathrm{cp}}} .
$$

2. Коэффициентом чувствительности, который представляет отношение момента начала срабатывания $\mathrm{T}_{\mathbf{0}}$ к величине момента Тср, когда предохранитель заканчивает срабатывание

$$
K_{\mathrm{Y}}=\frac{\mathrm{T}_{\mathbf{0}}}{\mathrm{T}_{\mathrm{cp}}} .
$$

Коэффициент Кч необходим для оценки выключающей способности предохранительных муфт, так как одни муфты немедленно выключают объект защиты по достижении предельного кругящего момента, а другие - лишь после дополнительного его превышения. Для полного выключения муфт необходимо, чтобы меньше требовалось дополнительного момента.

3. Коэффициентом точности ограничения нагрузки (точности срабатывания), представляющим отношение наибольшего и наименьшего кругящих моментов, при которых возможно срабатывание.

$$
K_{\mathrm{T}}=\frac{\mathrm{T}_{\max }}{\mathrm{T}_{\min }} .
$$

Чаще всего коэффициент точности срабатывания больше единицы. Желательно, чтобы он был ближе к единице, так как в этом случае предохранительная муфта работает надежнее, а качество защиты выше.

4. Коэффициентом динамичности, который представляет отношение максимального динамичного момента $T_{\text {д max }}$, возникающего при срабатывании муфты (или при её дальнейшей пробуксовке), к моменту регулировочному $\mathrm{T}_{\text {per }}$

$$
K_{д}=\frac{T_{A} \max }{T_{\text {per }}} \cdot
$$

5. Временем действия предохранительной муфты $t_{\text {д }}$. Его считают от начала срабатывания до момента начала снижения нагрузки. Быстрота действия предохранительной муфты должна соответствовать времени наступления аварийного состояния $t_{\text {ав }}$

$$
t_{\mathrm{aB}=\kappa_{\sigma} \mathrm{t}_{\mathrm{g}}},
$$

где $\mathrm{K}_{6}$ - коэффициент безопасности, значение которого следует брать равным 2-3 [2].

При аварийном состоянии объекта зашиты его наиболее слабое звено может разрушиться или в нем появятся значительные остаточные деформации. В этом случае работа узла или машины в целом становится невозможной.

Выбор типа предохранителя и разработка нового конструктивного решения, как отмечено в [3], сопряжены с решением комплекса вопросов. Предлагается технические объекты рассматривать во взаимодействии с внешней средой в виде единой системы, которая показывает взаимную связь предохранительной муфты и её элементов, лесохозяйственной машины и внешней среды, величины и характера изменения внугренних и внешних нагрузок, погодноклиматических условий и др. Основным в рассматриваемой системе следует считать предохранитель, так как именно он определяет качество защиты.

Стремление к совершенствованию средств защиты машин от перегрузок привело к большому разнообразию их конструкций. Отдельные предохранительные устройства близки в конструктивном исполнении, но в большинстве случаев резко отличаются. Разработка новых конструктивных решений продолжается, что говорит о важности нерешенных проблем защиты машин от перегрузок [4]. Здесь следует отметить, что при проектировании новых конструкций и 
выборе типа существующих необходимо использовать опыт смежных отраслей машиностроения, учитывать все полезное, что есть в существующих конструкциях.

В первую очередь надо стремиться брать стандартный тип предохранительной муфты, хотя это очень затруднительно вследствие невозможности вписания стандартных муфт в узлы лесохозяйственных машин. Причем как применяемые нестандартные, так и стандартные предохранительные муфты имеют существующие недостатки. Поэтому существующие ГОСТы на предохранительные муфты требуют пересмотра и введения в них других типов предохранителей с улучшенными характеристиками.

Вопрос выбора типа предохранительной муфты или её разработки тесно связан с одним из наиболее сложных положений - с выбором уровня параметра защиты. Для приводов различных сельскохозяйственных машин и станков $[5,6]$ предлагается уровень параметра защиты выбирать из условия полной передачи рабочих нагрузок объекта защиты. Для лесохозяйственных машин предлагается [7, 15] уровень параметра защиты устанавливать путем рассмотрения конкретной динамической системы машин с учетом действующих на нее сил. Более целесообразно уровень параметра защиты выбирать на основе экспериментальных данных с использованием основных положений теории выбросов случайной функции $[7,5,14,16]$.

Установка предохранительных муфт должна осуществляться в непосредственной близости к месту приложения нагрузки, то есть в рабочем органе. Однако такое не всегда возможно из-за конструктивной особенности машины и выполняемого ею технологического процесса. В этом случае предохранительное устройство должно быть установлено в таком месте кинематической цепи привода, от которого передаточное отношение до места приложения нагрузки постоянно. Постоянство передаточного отношения важно и с точки зрения стабилизации КПД данного участка. Существенное значение имеет место установки средства защиты от перегрузки при переходных режимах. Необходимо, чтобы коэффициент динамичности имел наименьшее значение [6].

Место нахождения наиболее слабого звена машины также имеет большое значение, так как динамические нагрузки при срабатывании предохранительной муфты в ведущей и ведомой частях системы относи- тельно расположенной муфты неодинаковы [5, 7].

Предохранительное устройство должно удовлетворять основным лесотехническим требованиям [8, 9]:

- обеспечивать нормальную работу лесохозяйственной машины и не влиять на её качественные показатели;

- желательно, чтобы предохранитель был выполнен в виде независимого узла;

- учитывать эксплуатационные условия: характеристику почвы (или других материалов, связанных с назначением машины), сроки работы, скорость движения агрегата и др.;

- исключить ложные срабатывания.

Чтобы не было ложных срабатываний или невыключений предохранительной муфты, должна производиться её регулировка на заданный момент ограничения нагрузки, для чего предохранительное устройство должно иметь специальный механизм. Регулировку следует производить через определенное время эксплуатации. Её должен выполнять квалифицированный специалист, ответственный за эксплуатацию машин с последующим пломбированием [5].

Конструкция и место расположения предохранителя должны обеспечить удобство обслуживания, регулировки, смазки, замены неисправностей, доступность осмотра и содержания в надлежащем виде, легкость монтажа и демонтажа. Предохранительные муфты должны обеспечить высокую прочность всей лесохозяйственной машины, причем это должно осуществляться без увеличения их массы.

Во всех случаях надо стремиться к созданию и выбору такого предохранительного устройства, чтобы оно обладало высокой надежностью и долговечностью. С увеличением срока службы предохранителя уменьшаются эксплуатационные и ремонтные расходы на всю машину.

Успешное проектирование или выбор типа существующих предохранительных муфт возможны в том случае, если есть расчетные зависимости по определению их основных параметров и характеристик. В противном случае они должны быть разработаны. Методы расчета предохранителей должны учитывать реальные физические явления, наблюдающиеся в практике.

На выбор уровня параметров защиты, конструкцию и место установки муфты предельного момента существенное влияние оказывает точность ограничения 


\section{Технологии. Машины и оборудование}

нагрузки и динамические явления, возникающие в элементах лесохозяйственных машин. Эти критерии являются основополагающими. Их надо учитывать комплексно, но для тихоходных приводов лесохозяйственных машин отдавать предпочтение следует точности срабатывания, для быстроходных - динамике [7].

Не меньшее значение имеет классификация предохранительных муфт. Она дает направление в ориентации конструктивных решений и их развития.

Известны классификации предохранительных муфт по ряду признаков $[6,10,11,12,13]$. Однако все они носят описательный характер, близки по сути и практически не отличаются друг от друга. По ним невозможно выявить взаимную связь между различными видами и группами муфт. В результате анализа существующих классификаций, работы лесных машин в реальных условиях эксплуатации и их защитных устройств разработана новая классификация предохранительных муфт для лесохозяйственных машин, в основу которой положены функционально-конструктивные признаки и связь между ними [7]. Хотя это первая попытка в систематизации предохранительных муфт лесохозяйственных машин, но уже и по ней можно выбрать или положить в основу разработки определенный тип предохранителя. В этой классификации в специальную группу выделены размыкающиеся муфты предельного момента. Отмечено, что такие муфты целесообразно использовать для защиты лесохозяйственных машин, подверженных частым перегрузкам. Размыкающиеся предохранительные муфты полностью снимают динамические нагрузки при пробуксовке и исключают износ рабочих элементов.

\section{Библиографический список}

1. Карамышев, В.Р. К повышению надежности лесных машин [Текст] / В.Р. Карамышев, Н.А. Бородин // Тезисы Всероссийской конференции Комплексная продуктивность лесов и организация многоцелевого (многопродуктивного) лесопользования. - Воронеж, ВГЛТА, 1996. - С. 160-161.

2. Карамышев, В.Р. Защита лесохозяйственных машин от перегрузок [Текст] / В.Р. Карамышев. Воронеж: Из-во ВГУ, 1991 - 168 с.

3. Справочник по муфтам [Текст] / Под общ. ред. О.А. Ряховского, С.С. Иванова. - Л.: Политехника, 1991. -383 c.

4. Карамышев, В.Р. Совершенствование защиты выкопачных лесохозяйственных машин от перегрузок [Текст] / В.Р. Карамышев, Н.А. Бородин // Матер. Всероссийской научно-технической конференции «Повышение технического уровня машин лесного комплекса», Воронеж, 1998. - С. 18.

5. Попов, Е.М. Исследование привода и предохранительных муфт сельхозмашин при перегрузках [Текст] : автореф. дис. ... канд. техн. наук. / Е.М Попов. - Воронеж, 1967. - 26 с.

6. Тепенкичиев, В.К. Предохранительные устройства от перегрузки станков [Текст] / В.К. Тепенкичиев. - М. : Машиностроение, 1968. - 122 с.

7. Карамышев, В.Р. Совершенствование защиты ротационных лесохозяйственных машин от перегрузок [Текст] : дис. ... докт. техн. наук. / В.Р. Карамышев. - Воронеж, 1988. - 445 с.

8. Нартов, П.С. Проектирование и расчет лесохозяйственных машин [Текст] / П.С Нартов. - Воронеж : ВГУ, 1980. - 192 с.

9. Посметьев, В.И. Расчет пневматического предохранителя лесного дискового культиватора [Текст] / В.И. Посметьев, В.И. Зеликов. - ВГЛТА, Воронеж, 1998. - 37 с.

10. Гонский, Г.Ф. Предохранительные устройства как средство повышения качества машин [Текст] : автореф. док. ... техн. наук. / Г.Ф. Гонский. - Харьков, 1965. - 44 с.

11. Поляков, В.С. Муфты [Текст] / В.С. Поляков, В.С. Барбаш. - М.-Л. : Машгиз, 1964. - 364 с.

12. Посметьев, В.И. Методологические основы повышения эффективности почвообрабатывающих орудий с помощью предохранителей [Текст] / В.И. Посметьев. - Воронеж, 1999. - 196 с.

13. Рекомендации СЭВ по стандартизации РС 2201-69. Муфты для соединения валов [Текст] (определение и классификация ),1970. - 37 с.

14. Subtantiation and evaluation of effectiveness of perspective constructions of forest tractors ancillary equipment [Text] / V.I. Posmetev, V.A. Zelikov, M.V. Drapalyuk, M.A. Latysheva, E.V. Shtalov // ARPN Journal of 
Engineering and Applied Sciences. - 2016. - Vol. 11. - no. 3. - pp. 1840-1855.

15. Hallman, R.G. Nuzsery eguipment survey zeport [Text] / R.G. Hallman, J. Lott // Proceedings of Westerm Forest Nursezy Council Meeting: August 5-7-Poztland, Oregon, 1974. -pp. 125-134.

16. Zelikov, V.A. Substantiation based on simulation modeling of hitch for tillage tools parameters [Text] / V.A. Zelikov, V.I. Posmetev, E.V. Latysheva // World Applied Sciences Journal, 2014, Vol. 30, no. 4, pp. 486-492.

\section{References}

1. Karamyshev V.R., Borodin N.A. K povysheniyu nadezhnosti lesnyh mashin [To improve the reliability of forest mashin] Kompleksnaja produktivnost' lesov $i$ organizacija mnogocelevogo (mnogoproduktivnogo) lesopol'zovanija. Tezisy Vserossijskoj konferencii [Integrated forest productivity and organization of multipurpose(mnogoproduktivnogo) forest management : Proceedings of All-Russian conference]. Voronezh, 1996, pp. 160-161.( In Russian).

2. Karamyshev V.R. Zashchita lesohozyajstvennyh mashin ot peregruzok [Protecting forest machines from overload]. Voronezh, 1991, 168 p. (In Russian).

3.Ryahovsky O.A., Ivanov S.S. Spravochnik po muftam [Reference couplings]. Leningrad, 1991, 383 p. In Russian).

4. Karamyshev V.R., Borodin N.A. Sovershenstvovanie zashchity vykopachnyh lesohozyajstvennyh mashin ot peregruzok [Improving the protection of forest machines vykopachnyh overload]. Mat. Vserossijskoj nauch-no-tehnicheskoj konferencii "Povyshenie tehnicheskogo urovnja mashin lesnogo kompleksa" [Mat . All-Russian scientific - technical conference "Improving the technical level of the machin es Forest Complex"]. Voronezh, 1998, p. 18. (In Russian).

5. Popov E.M. Issledovanie privoda i predohranitel'nyh muft sel'hozmashin pri peregruzkah avtoref. dis. kand. tehn. nauk. [Study the nature and safety clutches of agricultural machinery in case of overload: Author. Dis. cand . tehn . nauk]. Voronezh, 1967, 26 p. (In Russian).

6. Tepenkichiev V.K. Predohranitel'nye ustrojstva ot peregruzki stankov [Safety devices against overloading machines]. Moscow, 1968, 122 p. (In Russian).

7. Karamyshev V.R. Sovershenstvovanie zashchity rotacionnyh lesohozyajstvennyh mashin ot peregruzok Dokt, Diss. [Improving the protection of forest machines rotary overload. Dokt, Diss.]. - Voronezh, 1988, 445 p. (In Russian).

8. Nartov P.S. Proektirovanie $i$ raschet lesohozyajstvennyh mashin [Design and calculation of forest mashin]. Voronezh, 1980, 192 p. (In Russian).

9. Posmetyev V.I., Zelikow V.A. Raschet pnevmaticheskogo predohranitelya lesnogo diskovogo kul'tivator [Calculation of air fuse forest disc cultivator ]. Voronezh, 1998, 37 p. (In Russian).

10. Gonsky G.F. Predohranitel'nye ustrojstva kak sredstvo povysheniya kachestva mashin avtoref. dok. tehn. nauk. [Safety devices as a means to improve the quality of machines. Author. doctor. tehn. Sciences]. Kharkiv, 1965, 44 p. (In Russian).

11. Polyakov V.S., Barbash I.D. Mufty [Couplings]. Moscow-Leningrad, 1964, 364 p. (In Russian).

12. Posmetyev V.I. Metodologicheskie osnovy povysheniya ehffektivnosti pochvoobrabatyvayushchih orudij s pomoshch'yu predohranitelej [Methodological bases of increase of efficiency of tillers with fuses]. Voronezh, 1999, 196 p. (In Russian).

13. Rekomendacii SJeV po standartizacii RS 2201-69. Mufty dlja soedinenija valov [Cmea recommendations on standardization RS 2201-69. Shaft coupling]. 1970, 37 p. (In Russian).

14. Posmetyev V.I., Zelikov V.A., Drapalyuk M.V., Latysheva M.A., E.V. Shatalov E.V., Subtantiation and evaluation of effectiveness of perspective constructions of forest tractors ancillary equipment // ARPN Journal of Engineering and Applied Sciences, 2016, Vol. 11, no. 3, pp. 1840-1855.

15. Hallman R.G. Nuzsery eguipment survey zeport J.Lott. Proceedings of Westerm Forest Nursezy Council Meeting: August 5-7-Poztland, Oregon, 1974, pp. 125-134.

16. Zelikov V.A., PosmetyevV.I., Latysheva M.A. Substantiation based on simulation modeling of hitch for tillage tools parameters // World Applied Sciences Journal, 2014, Vol. 30, no. 4, pp. 486-492. 


\section{Сведения об авторах}

Бородин Николай Александрович - доцент кафедры механизации лесного хозяйства и проектирования машин, ФГБОУ ВО «Воронежский государственный лесотехнический университет имени Г.Ф. Морозова», кандидат технических наук, доцент, г. Воронеж, Российская Федерация; e-mail: Borodinnikol@mail.ru.

Князев Александр Владимирович - доцент кафедры механизации лесного хозяйства и проектирования машин, ФГБОУ ВО «Воронежский государственный лесотехнический университет имени Г.Ф. Морозова», кандидат технических наук, доцент, г. Воронеж, Российская Федерация; e-mail: sahsa-2013@yandex.ru.

Ткачев Виталий Викторович - доцент кафедры механизации лесного хозяйства и проектирования машин, ФГБОУ ВО «Воронежский государственный лесотехнический университет имени Г.Ф. Морозова», кандидат технических наук, г. Воронеж, Российская Федерация; e-mail: tka4iov.v@yandex.ru.

Четверикова Ирина Владимировна - доцент кафедры механизации лесного хозяйства и проектирования машин, ФГБОУ ВО «Воронежский государственный лесотехнический университет имени Г.Ф. Морозова», кандидат технических наук, доцент, г. Воронеж, Российская Федерация; e-mail: chivles@rambler.ru.

\section{Information about authors}

Borodin Nikolai Alexandrovich - Associate Professor Department of Forestry Mechanization and Machine Design, Federal State Budget Education Institution of Higher Education «Voronezh State University of Forestry and Technologies named after G.F. Morozov», PhD in Engineering, Associate Professor, Voronezh, Russian Federation; e-mail: Borodinnikol@yandex.ru

Knyazev Alexander Vladimirovih - Associate Professor Department of Forestry Mechanization and Machine Design, Federal State Budget Education Institution of Higher Education «Voronezh State University of Forestry and Technologies named after G.F. Morozov», PhD in Engineering, Associate Professor, Voronezh, Russian Federation; e-mail: sahsa-2013@yandex.ru

Tkachev Vitaliy Viktorovich - Associate Professor Department of Forestry Mechanization and Machine Design, Federal State Budget Education Institution of Higher Education «Voronezh State University of Forestry and Technologies named after G.F. Morozov», PhD in Engineering, Voronezh, Russian Federation; e-mail: tka4iov.v@yandex.ru

Chetverikova Irina Vladimirovna - Associate Professor Department of Forestry Mechanization and Machine Design, Federal State Budget Education Institution of Higher Education «Voronezh State University of Forestry and Technologies named after G.F. Morozov», PhD in Engineering, Associate Professor, Voronezh, Russian Federation; e-mail: chivles@rambler.ru.

DOI: $10.12737 / 19966$

удК 6313.634 .93

\section{МОДЕЛИРОВАНИЕ ПРОЦЕССА СОРТИРОВАНИЯ СЕМЯН}

кандидат технических наук, доцент А. В. Князев ${ }^{1}$
кандидат технических наук, доцент Н. А. Бородин

кандидат технических наук, доцент А. И. Максименков ${ }^{1}$

1 - ФГБОУ ВО «Воронежский государственный лесотехнический университет имени Г.Ф. Морозова», г. Воронеж, Российская Федерация

В статье представлено математическое описание процесса сортирования семян лесных культур по их размерным критериям на многоступенчатом вальцовом сепараторе. Получены регрессионные уравнения, позволяющие определить оптимальные конструктивно-технологические параметры сепаратора, при которых достигается максимальная эффективность процесса сортирования. Создание многоступенчатого вальцового сепаратора является перспективным направлением в решении вопроса сортирования и подготовки семян хвойных пород для высева их в питомнике. Он состоит из рамы, загрузочного бункера, механизма равномерной подачи в виде двух шлифованных 